\title{
Agenda 2063: Science, Technology, Engineering, and Mathematics (STEM) Education to the Rescue
}

\author{
Dr. Kehdinga George Fomunyam \\ Teaching and Learning Development Center, Mangosuthu University of Technology, Durban, South Africa.
}

\begin{abstract}
Agenda 2063 is an ambitious fifty (50) year plan detailing the aspirations and goals of the African continent for the future. Building on the strengths and weaknesses of previous plans as introduced by the OAU which later transformed to the AU, Agenda 2063 is built on seven (7) key aspirations, each with its own set goals that reflects the vision for a united and prosperous Africa. The study adopted a theoretical review by using literatures in line with the topic under consideration for careful analysis. It was found out that despite huge prospects for development in Africa using this agenda, some challenges which include the unavailability or lack of adequate investment in the human, natural, and financial capacity needed to achieve these future projections hamper the goals of Agenda 2063. To avoid these challenges that plagued previous plans for Africa, this study makes a case for the full integration of STEM education in the African education system especially in this era driven by technological innovations. This paper recommends an overhaul of the African education curriculum before this integration, so that African students can design solutions for real-life African problems.
\end{abstract}

Keywords: Agenda 2063, STEM, STEM education, Africa.

\section{INTRODUCTION}

Despite huge prospects for development in Africa both at national and regional levels, the continent has not been able to achieve sustainable economic growth and development, sociocultural development, as well as maintaining synergy between African economies since the Organization of African Unity (OAU) was established. The OAU was established in 1963 with the mandate to pursue political and socio-economic independence for the African continent (Ndizera \& Muzee, 2018). Prior to this time, Africa had struggled through colonialisation by foreign nations, slavery, and all kinds of racial exploitation. The struggle for independence was underway in many African nations and, towards the 1950s, most nations began to attain independence and gain freedom from their colonial masters. The need to restore the dignity of the African continent, promote liberalization, unity, and progress led to the formation of the OAU. The focus of the OAU was therefore channeled towards decolonization, independence, and the pursuit for collective prosperity
(European Commission, 2019; Ndizera \& Muzee, 2018). The OAU came up with several plans to promote political unity and economic emancipation in the continent, but these strategies and frameworks were hampered by a lack of clear vision, and the absence of continental unity.

The Organization of African Unity (OAU) was later transformed to the African Union (AU), so as to usher in new principles and elements that will resolve the problems faced by member states, as well as the economic, social, and political problems which reached crisis proportions in the 1980s(Tralac, 2017). These new initiatives were plagued by lack of integration, cooperation, capacity, resources, and political will to execute. In fact, initiatives adopted at the continental level were overshadowed by national plans endorsed by individual nations, thereby limiting these continental agenda's due to ineffective and inefficient participatory efforts (Ndizera \& Muzee, 2018; Tralac, 2017). In recent times, global changes and advancements has repositioned the needs of Africa to social and economic development to ensure global competitiveness as against the previous passion for political independence. This repositioning of Africa's Agenda to prioritize inclusive and sustainable growth and development led to the declaration of Agenda 2063 by the African Union in May 2013 when they celebrated their $50^{\text {th }}$ anniversary. Cole (2017) opines that the 50 -year vision and action plan was introduced with the intention of accelerating development and technological progress in Africa. In order to avoid the challenges that hampered previous agendas as introduced by the commission, Agenda 2063 was built on existing African frameworks, programs, declarations, and consultations of all stakeholders at the grass root level. Encapsulating all of Africa's aspirations for the future, the Agenda 2063 is rooted in Pan-Africanism and African renaissance with a blueprint for the transformation of Africa into a dominant player in the global forefront.

A 50-year plan is quite ambitious, and there is also no model rigorous enough to predict that far into the future but, Cole (2017) argues that Agenda 2063 is a flexible plan that can be adjusted as situations demand. Notwithstanding, this agenda faces several challenges which can limit its manifestation such as underdeveloped infrastructure, poverty, lack of finance and other resources, and a rapidly growing unskilled population to build a productive workforce that will deliver its benefits. As argued by the African Development Bank Group, Africa's population is young and growing with the prediction 
of 250million Africans within the ages of 15 and 24-years old living in Africa by the year 2020 (Cole, 2017; African Union Commission, 2014). This implies that the future of Africa is in the hands of these unskilled young minds and as such, investment in educating them should be a priority. Not just basic education, but quality education with focus on the fields of Science, Technology, Engineering, and Mathematics (STEM). This is because these are fields that would rule the world in this era of the fourth industrial revolution which has been progressing since the beginning of the $21^{\text {st }}$ century. To this end, this paper sets out to critically analyze Agenda 2063 and its key demands, while exploring its prospects and exposing its challenges. This is done with the intent to project STEM education as a response to these challenges and the uncertainties that awaits the African continent to ensure it glides through the $21^{\text {st }}$ century as a global competitor.

\section{AGENDA 2063: A CRITICAL ANALYSIS}

Prior to Agenda 2063, the AU has introduced several other initiatives and strategies to better the lives of Africans. Some of these plans include the Lagos Plan of Action, the Abuja Treaty, the New Partnership for Africa's Development (NEPAD), the Comprehensive Africa Agriculture Development Programme (CAADP), Accelerated Industrial Development(AIDA), the Minimum Integration Programme (MIP), Programme for Infrastructure Development in Africa (PIDA), AU/NEPAD Science and Technology Consolidated Plan of Action, Africa's Agro-Industry and Agribusiness Development Initiative (3ADI), and the Social Policy Framework. Agenda 2063 is quite different as it is result oriented and, comes with a different approach, a better communications strategy, a clear resource mobilization strategy, coherent policies, and a nature that is result oriented (Viswanathan, 2018). This Agenda was introduced in 2013 and adopted in January 2015 as a continental based development plan for a better future for Africans. Agenda 2063 is a strategic approach designed by African leaders to effectively learn from its past and build its future, such that remarkable socioeconomic transformation will be recorded within the next 50 years. As stated by the African Union:

The genesis of Agenda 2063 was the realization by African leaders that there was a need to refocus and reprioritize Africa's agenda from the struggle against apartheid and the attainment of political independence for the continent, which had been the focus of the Organization of African Unity (OAU), the precursor of the African Union; and instead to prioritize inclusive social and economic development, continental and regional integration, democratic governance and peace, and security amongst other issues, aimed at repositioning Africa to becoming a dominant player in the global arena. (African Union, 2013, p. 1).

The African Union is simply implying that this agenda will build on the strength and weaknesses of previous plans and will be driven by citizens of Africa to boost Africa's economic growth and overall development, leading to a total transformation of the continent within the next 50 years. Agenda 2063 has its major standing in Pan Africanism and aims at providing a template for correcting injustices to help in ensuring that the 21 st century aspirations of Africa are met. This agenda also aims to synergize and galvanize action in Africa and beyond towards ensuring the betterment of the continent, harness and leverage on Africa's massive resources, geopolitical position to ensure equitable growth and development, fight poverty, ensure the development of human capital, social assets and infrastructure (AUC, 2015a). Agenda 2063 has in it the eight priorities of the $50^{\text {th }}$ anniversary solemn declaration that includes, African identity and renaissance fight against colonization and right to self-determination, integration agenda, agenda for social and economic development, peace and security agenda, democratic governance, shaping Africa`s destiny and the position of Africa in the world. It is an agenda built on seven (7) key aspirations, each with its own set goals that reflects the vision for a united and prosperous Africa.

The first aspiration is a prosperous Africa based on inclusive growth and sustainable development. This is all inclusive as it seeks to ensure high standard of living and quality of life and wellbeing, ensure that citizens are well educated and have an overhaul in their skill makeup underpinned by science, technology, engineering and, mathematics(STEM) (African Union, 2014). The African union further maintains that the first aspiration also seeks to have healthy and well-nourished citizens with long life span, ensure good communication flows between cities, per-urban and rural communication, economic transformation to ensure that there is shared growth generated through massive entrepreneurship and befitting jobs for all, revitalize agricultural production using modern methods and ensure adaptation to preserve the African natural environment. According to AFDB, AU AND UNECA (2013), a high standard of living for Africa as a key component of the first aspiration will be demonstrated on increased per capita income to a level that is at least 10 times the value gained in 2013 which ranged from USD 1878 to USD 18878-20000. Under the first aspiration, there will be reduction in number of people holding jobs that are predisposed to risk and other vulnerabilities, ensure an increase in employment opportunities for all especially those within the youthful demography, provide decent jobs to those that are outside the youthful demography which will be a major key in driving broad-based increases in incomes and better livelihoods, social cohesion and stability for all. The first aspiration also seeks to promote standard of living as a fundamental right for citizens in Africa. By 2063, citizens of Africa should be able to get access to affordable social security and improved healthcare, which cuts across all classes and people especially the mental and physically impaired people, elders and children. They are mostly predisposed to vulnerabilities and they must be focused on to ensure a broadbased approach to a prosperous Africa. The Africa of 2063 will have humanity at its centre, and it will be a compassionate and caring continent (African Union, 2014).

The second aspiration of Agenda 2063 is based on Africa's 1963 vision to have an integrated continent that is politically united, premised on the ideals of Pan-Africanism and the vision of Africa's renaissance. According to Agenda 2063 the framework document of this agenda, Africa by 2063 will have developed to be a sovereign, independent and continent capable of accomplishing economic prosperity and political integration. With the solidarity that came from the freedom from slavery 
and colonial deprivation, there will be renewed interest in solidarity and unity of purpose, and colonialism will finally collapse in all African territories. There will be demands to put an end to the illegal occupation of the Chagos Archipelago, the Comorian Island of Mayotte and clearly ensure the right to selfdetermination of the citizens of Western Sahara. By 2063, Africa will be completely united and there will not be differentials at all levels, there will also be world class infrastructure that spans the entire continent.

Infrastructures needed to support growth and development in Africa will be put in place and this includes high speed rail network, shipping lines, sea and air transport, increased investment in ICT and digital economy. There will be continental high speed train network that will ensure that all major capitals of the world are connected and the highways will be used for pipeline for gas, oil, water and broad band cables. This will be a boost for production and manufacturing, research and development in Africa. By 2063, there will be full liberalization of air transport and full implementation of the Yamoussoukro decision by adopting all treaties and protocols associated with it making Africa a major aviation spot for regional integration, job creation and economic transformation. Providing this world class infrastructure will provide a platform for ensuring the growth of intra-trade from less than 12percent in 2013 to close to 50percent of Africa's trade portfolio by 2045. This will strengthen growth of pan African companies in key sectors such as manufacturing, mining, finance, food and beverages, hospitality and tourism, pharmaceuticals, fashion, design, fisheries and ICT (AU, 2014). Free movement will characterize Africain terms of factor (labour, capital and skills), people mobility and there will be increase in trade and affinity between continental institutions such as the African central bank will be fully operational. Intra-Africa trade will receive a boost and the continental free trade area (CFTA), the Africa monetary Union and all related financial setup will be put in place.

The third aspiration posits that by 2063 , the continent can boast of good governance, democracy, respect for human rights, justice and the rule of law. This is because all culture of good governance, democratic values, gender equality and respect for human rights will be upheld thereby ensuring that elders, children, women and other vulnerable people will have equal rights as others in the society. Africa will become a continent where democratic values are taken as king, where there is conformity with all universal principles of human right, where law and order is duly maintained, where all charter on human rights and peoples' rights are respected. The agenda assumes that all forms of corruption would have been handled by 2063 and, institutions saddled with this responsibility will be strengthened and there will be effective design and implementation to make this possible across board. Africa as a continent will also witness transparent, free, fair and credible elections that will ensure multi party plural systems, free and fair field of play that allows for meaningful competition, education and liberation of the minds of the electorate to make good decision in terms of voting and upholding the pan African principle, equality, diversity, excellence and solidarity, free press, adherence to the universal principles of human rights, justice, law and order, capable institutions and effective leadership at all phases (Africa Union, 2014). The fourth aspiration of agenda 2063 according to-as postulated by the AU is the actualization of a peaceful and secure Africa that will be devoid of conflict, wars, ethnic rife at all levels. There will be intra-state and inter-state harmony, and mechanisms will be put in place to nip in the bud any attempt that might result to disunity in the society. Ethnic supremacy, racial segregation, terrorism and other criminal activity will be reduced which will ensure that there is a prosperous, integrated and safe continent that will entrench peace as a culture. The Agenda projects that there will be mechanisms that will facilitate conflict management, and premium will be placed on conflict resolution even before it escalates. The borders will be secured, with an assurance of regional security, as the air, land and waterways will be safe for all.

The fifth aspiration for agenda 2063 envisions an Africa with a strong cultural identity, common heritage, values and ethics. As stated by the African Union, the goal of this aspiration is to "inculcate the spirit of Pan Africanism, tapping Africa's rich heritage and culture to ensure that the creative arts are major contributors to Africa's growth and transformation, and restoring and preserving Africa's cultural heritage, including its languages." This implies that our cultural values are will be upheld, and as a result of cultural patrimony that has helped human progress in Africa, there will be renewed focus on strengthening our African cultural values and identities, to achieve an Africa where pan Africanism is fully entrenched and African cultural renaissance is at the fore. Unity in Africa is important as a demand of Agenda 2063 and fruits and ideals of pan Africanism will be manifested in the continent. The sixth aspiration is based on an developing an Africa that is people driven, relying on the potential of African people especially women and youth and caring for children. People will be the focus of this aspiration, and all citizens will be involved in decision making to ensure an inclusive approach which will in the long run contribute to sustainability. No individual regardless of class, age etc. will be left behind in all decisionmaking process. Gender equality will be the norm and there will be equal access to social and economic opportunities for all. The Africa of 2063 will ensure gender equality across all dimensions, engaged and empowered youth is the order of the day, children are well taken care of and cherished, the role of women for transformation will also be considered (AU, 2014). The seventh aspiration of Agenda 2063 focuses on developing an Africa that is a strong, united, resilient and influential global player and partner. It envisions Africa as a major player, globally shaping all aspect of commerce, industry, manufacturing, mining etc. Africa will be a major partner in global affairs and peaceful co-existence. The aspiration projects that Africa will assume its rightful position in maintaining global peace and security, by having a permanent seat at the UN security council. By self-re-empowerment, Africa will determine its own future, leading the course for effective partnership with external partners (AU, 2014; EU, 2019).

These aspirations and goals are a great deal, and the realization of these visions are on a high stake, but the United Nations argues that they are all valid and can be achieved if all stakeholders involved diligently work together. A strategic Ten 
(10) year implementation plan has already kicked off to ensure that Agenda 2063 achieves its visions for an improved Africa but, several challenges have been identified already (Ndizera \& Muzee, 2018). These challenges are capable of disrupting the 2063 action plan, and therefore needs to be addressed squarely. For one, some scholars insist that the agenda is over ambitious, and the feasibility of its achievement within the stated time frame is unrealistic. Other challenges include the unavailability or lack of adequate investment in the human, natural, and financial capacity needed to achieve these future projections. Although the agenda articulates a financial strategy that is based on domestic resource mobilization, the AU does not possess the adequate financial resources, and also lacks the needed partnership policies and strategies (DeGhetto et al., 2016; Ndizera \& Muzee, 2018; Cole, 2017). Naturally, Africa is endowed, but these natural resources are yet to be properly managed decades after they have been discovered and, the continent is yet to reflect yields from these resources. Most African nations still suffer high rates of poverty, hunger, and inequality. The African continent is still largely natural resource based, with the routine of mining these resources, exporting them to developed countries, and importing finished products which cannot be produced in Africa.

As opined by Khalil and Osman (2017), times have changed and globally, there has been a paradigm shift towards creating knowledge-based economies for the current modernised era. The world is fast becoming a digital globe ruled by scientific innovations and advances in communication, and information technology. For nations with the right knowledge and skills, this era of digitalisation and globalisation will be liberating because, economies that rely on knowledge unlike economies that rely on natural resources which is finite, depends on the limitless creativity, and talents of its people to generate economic value (Schilero, 2013). This affects Agenda 2063 as it is primarily based on development predicated on self-reliance of the African people, and it embraces the Pan Africa vision of "an integrated prosperous and peaceful Africa, driven by its own citizens, and representing a dynamic force in the international arena."(A.U, 2015. p.3). This explains the importance of human capital required to achieve these plans especially since investment in education by African nations is inadequate. In the forefront of the challenges faced by Agenda 2063 is the lack of a skilled population, with low quality education (DeGhetto et al., 2016; Ndizera \& Muzee, 2018; Cole, 2017). As stated by Haddad (2017), in a report by the African Development Bank reveals that young people under the age of 15 make up $40 \%$ of Africa's population, with another $20 \%$ aged between 15 and 24 years. These young minds if properly educated can lead Africa to its desired vision for growth and prosperity because, a direct positive relationship between education and economic growth have been established. Therefore, creating a knowledge-based economy is a lifeline for the African continent especially in this era of the $21^{\text {st }}$ century, where progress and growth is a function of knowledge and ideas (Shihab, nd.; Viswanathan, 2018).

It is worth noting that Agenda 2063 took into consideration the need to revamp the education sector in Africa, one of its key demands highlights the investment in skills, science, technology, engineering and mathematics (STEM) education.
This is a step in the right direction in this era of innovation where Science and technology has become key towards development (Khalil \& Osman, 2017). However, this paper proposes a complete refocus of the African Agenda on educating its populace in the fields of Science, Technology, Engineering, and Mathematics (STEM). These are fields that largely drive innovation and as such, should be a priority for the African continent. The plans of this agenda which is largely built on aspirations for inclusive growth and sustainable development, with emphasis on grooming Africa to become an influential global player and partner, relies on bringing Africa up to speed with global changes, especially as it affects education in this era dominated by advanced technological innovations.

\section{STEM EDUCATION: AN INFINITE ECONOMIC RESOURCE}

The major focus of Agenda 2063 is sustainable economic growth for the African continent because, the independence of Africa is directly dependent on its economic strength. Studies have revealed that in accessing economic growth, two traditional inputs are of great importance and they are labour and physical capital. As stated by Croak (2018), when output is perceived as growing faster than the contributions of these two inputs, economists agreed that the factor at play is the quality of labour, or the technological know-how of the inputs. This implies that the quality of education possessed by the human capital of an economy determines the pace of its progress. Thus, a knowledge-based economy is key to economic progress, and a well-trained workforce will ensure its sustenance. This exposes the important role that education has to play in the actualization of the goals of Agenda 2063. The structure of the global education system is changing due to the emergence of an era driven by technology. Education systems have changed in order to adapt to the changes of the $21^{\text {st }}$ century, and education is now based on knowledge use and synthesis, building vital skills in collaboration, communication, critical thinking, and creativity. The world is currently focused on technological innovations and advancements, and STEM fields will rule the world in the future. Disruptive technologies such as artificial intelligence, renewable energy, and internet of things, cloud, advanced robotics and autonomous vehicles have been predicted to reshape the world in the $21^{\text {st }}$ century (Fisk, 2017). These will affect all sectors of the global economy and education must improve to adapt to the changes it will bring. STEM education has been identified as a viable approach to be utilized in the education sector and have become top priority for global businesses and governments as it is in the heart of our fast-moving technology-driven world (Sahin, 2016).

Taking a cue from historical perspective, STEM education was nomenclature science, mathematics, engineering and technology (SMET) (Sanders, 2009), and it was created by the national science foundation (NSF) as a new initiative which will saddle all students with critical thinking skills vital for making them thrive as creative problem solvers and make them potentially marketable in their career. STEM education is a composite of four disciplines which are science, technology, engineering and mathematics. Science is the systematic study 
of the nature and behaviour of the material and physical universe which is predicated on observation, experiment and measurement and formation of laws aimed at describing these facts in general parlance. Technology is defined as that branch of knowledge which involves creation and application of technical methods and their synergy with life, society and the environment using the tools of industrial arts, engineering, applied science and pure science. Engineering on the other hand is a branch of science, where practical application of knowledge of pure sciences, physics or chemistry are applied in the construction of engines, bridges, buildings, mines, ships, plants etc. While mathematics is a group of related science which consist of algebra, geometry, calculus which studied numbers, quantity, shapes and space and their interrelationship using specific notations (Science, 2012; Technology, 2012; Engineering, 2012; Mathematics, 2012). These disciplines can be taught in isolation, but STEM education involves an integration of all four disciplines. It is by far more than just a convenient integration of these disciplines, rather it encompasses real world, problem-based learning that links the disciplines through cohesive and active teaching and learning approaches. As argued by Siekmann and Korbel (2016), STEM education and training establishes relationships between the four disciplines with the objective of expanding people's abilities by supporting technical and scientific education with a strong emphasis on critical and creative-thinking skills. The STEM education approach is interdisciplinary, Trans disciplinary, cross disciplinary, and outcome-focused with the aim to solve real-world challenges. It is an integrative approach to curriculum and instruction and is based on constructivism and construction with the purpose of inspiring creativity, inquisitive thinking, and teamwork (Wise et al. 2015). Thus, STEM education is Africa's tool to adjust to the growing technological trend as it will develop the limitless economic resource obtainable in a knowledge-based economy, by providing new frameworks for African young minds, to develop skills needed to thrive in this digital era.

As revealed by the United Nations, by the end of the twenty first century, Africa's population will be $40 \%$ of the global population and this typifies a significant rise from $9 \%$ in the 1950s (UN, 2015). Africa will have about two billion people by 2050 and this increase in population will come with various challenges such as the loss of arable lands, leading to inadequate food production and availability. One of the goals of the first aspiration of Agenda 2063 is to radically transform African agriculture, to enable the continent feed itself, and be a major player as a net food exporter. This goal is not new to the African Union as previous programmes such as the Comprehensive Africa Agricultural Development Programme (CAADP) and the AU-NEPAD agricultural programme were initiated for the same purpose. These strategies are already past a decade and even though some benefits were recorded, agriculture in Africa is still discussed in the context of hunger and malnutrition (Mbaabu, 2017; UN, 2014). Many African farmers lack the necessary skills and technological know-how to increase the quality and quantity of their agricultural production. Most are unaware of new farm management software that improve the farming system and makes it simpler, greenhouse technologies, technology for effective diagnosis and treatment of livestock, and $21^{\text {st }}$ century mechanization technological equipment (Seager, 2014). Increasing knowledge of Africans through STEM education and building on existing technology in the field of agriculture is the solution to other goals listed in the agenda. A technological skilled African populace in the field of agriculture will positively affect the issues of poverty, unemployment, and food security as desirably stated in the Agenda.

As stated by the World Economic Forum, 75million jobs could be displaced by 2022, but new technologies will also create 133 million new jobs for people who are trained to work with machines and data (WEF, 2016). Five trends will impact growth throughout 2022 and they are, advances in mobile internet, advances in cloud technology, advances in artificial intelligence, increase in the availability of big data, and the increase in the adoption of new technology (WEF, 2018). All five trends are technologically related and will therefore lead to an increase in demand for technology inclined employees globally. This implies that the future workplace will be dominated by technologically inclined individuals and Africa can only compete globally if it prepares its citizens. African Union agenda 2063 identifies one of its goals as raising well educated citizens and skills revolution underpinned by science, technology and innovation. With a drive to have at least $70 \%$ of all high school graduate to have access to tertiary education in science and technology (AU, 2015). STEM education is a veritable tool in preparing Africans to occupy the future workplace and tackle the unemployment challenge facing the African continent. Producing science inclined leaders also directly affects the third aspiration for an Africa of good governance, with the emergence of development-oriented and visionary leadership.

Leadership has been a major determinant in the production of successful and failed nations alike, most nations credit their growth and progress to the presence of goal-oriented leaders in the sphere of politics (Punch, 2017). A technologically inclined leadership will be ambitious about evolving the economy and its citizens to become knowledge-based and technologically driven, thereby tilting the African continent to the right direction. This involves providing the needed technologies necessary for transforming Africa from dependence on natural resources, to dependence on the limitless economic resource of creativity and talent. As opined by the Rwandan president Paul Kagame in 2016, "in the developing world, science is important in ensuring socio-economic transformation which is achievable by bridging the gap between Africa and the developed world (TWA'S , 2016). Leveraging on the power of STEM education, there will be advances in sciences especially in medical science which has a bearing on reduction of child mortality and ensures that a longer life span and fertility rate is achieved in Africa. This is in line with the first aspiration of Agenda 2063 which has access to a high standard of living, quality of life, sound health and well-being as one of its sub-components. In broad parlance, Agenda 2063 aims to realize a prosperous continent saddled with the means and resources necessary for development through science, technology and innovation (STI, 2014) 
International Journal of Engineering Research and Technology. ISSN 0974-3154, Volume 13, Number 7 (2020), pp. 1603-1609

(C) International Research Publication House. https://dx.doi.org/10.37624/IJERT/13.7.2020.1603-1609

\section{CONCLUSION AND RECOMMENDATION}

This research sought to inform the discourse on Agenda 2063 and how STEM education can come in as a veritable option to achieving it. Agenda 2063 is vital for the prosperity and transformation of Africa as a continent and efforts must be directed towards achieving its aspirations and goals. Agenda 2063 like some other developmental agenda is complex and it has with it many demands and aspirations and being in its initial stage, there is a need to shed more light on some of the key demands and its components. Therefore, this research outlined an analysis of Agenda 2063, and makes a case for the full integration of STEM education in the African education system. This paper recommends an overhaul of the African education curriculum before this integration, so that African students can design solutions for real-life African problems. The education curriculum in Africa is designed after models and paradigms that have little or no relevance to life in Africa. The African curriculum lacks interactive and engaging content to facilitate $21^{\text {st }}$ century learning and is mostly filled with facts and information instead of ideas and concepts (Kaya \& Seleti, 2014).

The fifth aspiration of Agenda 2063 envisions restoring and preserving Africa's cultural heritage, including its languages. The goal of this aspiration is to inculcate the spirit of Pan Africanism in African citizens (AU, 2014). Education and most importantly STEM education can provide valid solutions to ensure that these goals are achieved but first, education in Africa should no longer be designed to systematically dismiss the intrinsic value of African culture, language, customs, and practices from the curriculum. The African curriculum should be structured to encourage cognitive flexibility and emotional intelligence, it must be culturally attuned creating adaptive and flexible minds as these are the demands of the projected fastpaced future. STEM education encourages cognitive flexibility, creative thinking and problem-solving abilities, these are the skills Africa needs to compete in today's globalized world.

\section{REFERENCES}

African Union, (2013). Agenda 2063: The Africa We Want. Published June 10, 2013. Retrieved From: http://www.au.int.

African Union Commission (AUC) (2015a). Agenda 2063: The Africa We Want, (April) 1-24.

African Union Commission, (2014), Science, Technology and Innovation Strategy for Africa https://au.int/sites/default/files/newsevents/workingdocuments /33178-wd-stisa-english_-_final.pdf.

African Union Commission, Agenda 2063. (2015) The Africa We Want (Addis Ababa: African Union), accessed 16 August 2016, url: http://www.agenda2063.au.int/en/home

Angier, N. (2010). Stem education has little to do with flowers. New York Times. Retrieved from http://www.nytimes.com/2010/10/05/science/05angier.html? pagewanted=all.

Background of Ohio State. (2012). Retrieved January 21, 2012, from http://ucat.osu.edu/read/teaching/background_osu/background _print.html

Cole, L. (2017). Key Issues on Agenda 2063 and Their Relevance to the Education sector in Africa. Global Partnership for Education

Croak, M. (2018). The Effects of STEM Education on Economic Growth. Honors Theses 105. Retrieved From: https://digitalworks.union.edu/theses/1705

DeGhetto, K., Gray, J.R., \& Kiggundu, M. N. (2016). The African Union's Agenda 2063: Aspirations, Challenges, and Opportunities for Management Research. Africa Journal of Management, 2(1): 93-116

Engineering. (n.d.). Dictionary.com Unabridged. Retrieved May 20, 2012, from http://dictionary.reference.com/browse/engineering.

European Commission. (2019). Agenda 2063: The Africa We Want. Knowledge for Policy Published 9 April 2019. Retrieved From

http://www.ec.europa.eu/knowledge4policy/publication/agend a-2063-africa-we-want

EY (2017), 'EY's Attractiveness Program Africa: Connectivity redefined", May 2017, http://www. ey.com/Publication/vwLUAssets/ey-attractivenessprogramafrica-2017-connectivity-redefined/\$FILE/ey-attractivenessprogram-africa-2017-connectivityredefined.pdf (accessed 20 May 2017).

FAO, IFAD, UNICEF, WFP AND WHO (2017). The state of food security and nutrition in the world 2017. Building resilience for peace and food security. Rome, FAO. Retrieved from http://www.fao.org/3/a-17695e.pdf

Fisk, P. (2017). The Fourth Industrial Revolution...How 12 Disruptive Technologies Will Reshape Our World... and Their Opportunities for Your Business. Retrieved From: http://www.geniusworks.com

Good Governance Africa (2012) Africa's Natural Resources: If we are so rich, why are we so poor? The Journal of Good Governance Africa 1-35.

Kaya, H.O., \& Seleti, Y. N. (2014). African Indigenous Knowledge Systems and Relevance of Higher Education in South Africa. The International Education Journal: Comparative Perspectives, 12(1):30-44

Kelly, B. (2012, September). Stem: What it is, and why we Should Care. U.S. News and World Report, Retrieved from: http://money.usnews.com/money/careers/articles/2012/09/10/s tem-what-it-is-and-why-we-should-care

Khalil, N.M., \& Osman, K. (2017). STEM-2Ks Module: Fostering $21^{\text {st }}$ Century Skills Through Integrated STEM: K-12 STEM Education, 3(3): 225-233

Haddad, L. (2017). Africa and Europe: The Thorny Question of Migration. Al Jazeera, December 8, 2017. Retrieved From: https://www.aljazeera.com 
International Journal of Engineering Research and Technology. ISSN 0974-3154, Volume 13, Number 7 (2020), pp. 1603-1609

(C) International Research Publication House. https://dx.doi.org/10.37624/IJERT/13.7.2020.1603-1609

Mathematics. (n.d.). Collins English Dictionary - Complete \& Unabridged 10th Edition. Retrieved May 20, 2012, from Dictionary.com website: http://dictionary. Reference.com/browse/mathematics.

Mbaabu, A. (2017). Encountering Africa's Agriculture Challenges in its Cities Morning Traffic. Africa in Focus, March 29, 2017. Retrieved From: http://www/brookings.edu

Mervis, J. (2010). Innovations in STEM Education: A Conversation with PCAST's Jim Gates. Retrieved June 7, 2011 from

http://news.sciencemag.org/scienceinsider/2010/04/innovation s-in-stem-education-a-.html.

National Aeronautics and Space Administration, (2012). Nasa fy 2012 budget estimates, education. Retrieved from website: http://www.nasa.gov/pdf/516643main_NASA_FY12_Budget _Estimates-Education.pdf.

National Aeronautics and Space Administration. (2008). Sputnik and the dawn of the space age. Retrieved November 5, 2011, from http://history.nasa.gov/sputnik.

of organization studies (pp. 375-408). Newbury Park, CA: Sage

Ndizera, V., \& Muzee, H. (2018). A Critical Review of Agenda 2063: Business as Usual. African Journal of Political Science and International Relations, 12(8): 142-154

Pacanowsky, M., \& O'Donnell-Trujillo, N. (1983). Organizational Communication as Cultural Performance. Communication Monographs, 50, 126-147.

Punch (2017). Nigeria's Quest for Visionary Leadership. Published April 21, 2017. Retrieved From: http://www.punchng.com

Putnam, L. L., Phillips, N., \& Chapman, P. (1996). Metaphors of Communication and Organization. In S. R. Clegg, C.C. Hardy \& W. R. Nord (Eds.), The handbook

Sahin, A. (2016). STEM Education and Why it is Important for Countries' Global Leadership. The Fountain Magazine, Issue 112, Published 1 July 2016.

Sanders, M. (2009) STEM, STEM education, STEMmania. The Technology Teacher, 68(4).20-26.

Science. (n.d.). Collins English Dictionary - Complete \& Unabridged 10th Edition. Retrieved May 20, 2012, from Dictionary.com website:

http://dictionary.reference.com/browse/science.

Seager, C. (2014). Six Innovations Revolutionising Farming. The Guardian Published 8 July, 2014. Retrieved From: http://www.theguardian.com

Shihad, M.(nd). Economic Development in the UAE. Retrieved From: http://www.pdfs.semanticscholar.org

Taylor, B. C. (1999). Browsing culture: Membership and Intertextuality at a Mormon Bookstore. Studies in Cultures, Organizations and Societies, 5, 61-95.

Technology. (n.d.). Dictionary.com Unabridged. Retrieved May 20, 2012, from: http://dictionary.reference.com/browse/technology
Tralac (2017). African Agenda 2063: What Progress Since Adoption in 2015. Published 26 ${ }^{\text {th }}$ January 2017. Retrieved From: http://www.tralac.org/news/article/11177

TWAS's 27th General Meeting (2016), The World Academy of Sciences, https://twas.org/meeting/twass-27th-generalmeeting.

United Nations, World Population Prospects. (2015). The 2015 Revision. New York: United Nations. https://esa.un.org/unpd/wpp/publications/files/key_findings_w pp_2015.pdf.

Viswanathan, H. H. S. (2018). Africa's Agenda 2063: A Document of Hope. ORF Issue Brief, Issue No. 237. Retrieved From: http://www.orfonline.org.

Whitehouse.gov (2011). Remarks by the President in State of Union Address. Retrieved January 10, 2012, from http://www.whitehouse.gov/the-press-

office/2011/01/25/remarkspresident-state-Union-address 